\title{
PLANTS AND ETHNOVETERINARY PRACTICES IN SRI LANKA
}

\author{
A N F Perera and E R K Perera \\ Department of Animal Science, Faculty of Agriculture, \\ University of Peradeniya.
}

Ethnoveterinary practices in Sri Lanka were in use from time immemorial. This system of treatments rely on the herbal species available and their medicinal value. These traditional practices descended from generation to generation had become a culture in the socioeconomic life of the people and the ones who practice these traditional systems of treatment possessed a high stittus in the socicty. The evidence of practising this system of treatments is not confined only to Sri Lanka. but to the whole of Asia and Africa. In Asia it is believed that this is one of the major branches of Ayurveda. In India, enthnoveterinary practices using various plants were recorded during 1200 B.C. Even during King Asoka's period these herbal based treatments were used to treat animal. The Sri Lankan ethooveterinary practices has its roots from India. According to the history, king Rawana has a team of physicians to treat animals headed by Sushena. With Mahindat a group of Ayurvedic scholars had also arrived and settled at Anuradhapura. In the 3 century, king Dutugemunt has his physicians treated his Royal elephan. King Buddadasa (337 to 365 A.D.) himself was a physician and treated animals. In addition to Ayurveda, time to time Siddha system and Unani systems were introduced to Sri Lanka by the Hindu Tamils and Muslims, respectively.

Sri Lanka being an island and its strategic location. it is rich in llorist biodiversity to accommodate many species of plants both endemic and indigenous. These plants have been widely used in the Ethnoveterinary practices. Almost all the plant parts are used in treatment and commonly called "pas panguva" including llower, lruit, leal", whole plant, rhizome, root bark, seed, stem and juice. The active ingredients are alkaloids, polyphenolic compounds, saponin, glucoside, essential oils, sterol, inorganic and organic salts etc. These medicinal plants are used in the Ethnoveterinary practices as decoctions. infusions, powder, juice, poultice or paste. bolus etc. These preparations are used in drenching, force feeding, topical application, nasal application, vaginal application, anal application, fumigation and hanging houquet. Presently, many plant species of medicinal value and their populations are rapidly diminishing due to so called development and lack of awareness. On the other hand these traditional systems are either not passed down to next generation or the present generation is not interested. Therefore. they are subjected to a thatural death with time. Another aspect for the rapid disappearance of this traditional treatment system is the invasion hy the allopathic therapy.

Effective action is needed to both conserve these traditional Elhnoveterinay systems and propagate and conserve these medicinally important plants for the future.

Procesedings of the Fourth Annual Forestry and Environment Symposium 1998 of the Department of Forestry and Envirommental Science, University of Sri Jayewardenepura, Sri Lanka 